\title{
FILSAFAT PANCASILA DALAM PERSEPEKTIF HINDU
}

Oleh

Ni Gusti Ayu Kartika

\begin{abstract}
Pancasila is not just born, but through a very thorough planning process and reviewed by National figures through the session of the Preparatory Committee for the Preparation of Independence (BPPK). Pancasila as the foundation of the philosophy of the state of the Republic of Indonesia has the composition of five precepts which is a unity and unity and has the nature of the unity of the absolute, which is the nature of the monodualist nature as individual beings as well as social beings, and position as a personal being that stands alone and simultaneously also as a creature of God. The consequences of Pancasila as the basis of the state of Indonesia are all aspects in the administration of the state covered by the values of Pancasila which is the human nature that monodualis.
\end{abstract}

Keywords: Pancasila

\section{PENDAHULUAN}

Dalam perkembangan ilmu pengetahuan, filsafat sesungguhnya merupakan titik awal dari munculnya ilmu pengetahuan tersebut. Berawal dari titik tersebut, manusia mengembangkan pikiranpikirannya menjadi sebuah teori, ilmu, maupun landasan yang pada akhirnya mereka pilih sebagai pedoman mereka. Bercermin dari perkembangannya tersebut, maka wajar bila dikatakan bahwa sebenarnya manusia senantiasa berfilsafat selama hidupnya. Dari banyaknya filsafat yang muncul dari pemikiran seseorang, nantinya akan terdapat beberapa filsafat yang akhirnya terpilih dan diakui oleh sekelompok orang. Dengan demikian filsafat tersebut menjadi jalan hidup (way of life) bagi kelompok yang menggunakannya.

Betapa luas pemikiran, pandangan dan wawasan the pounding father, yang telah berhasil meletakkan nilai-nilai etika dan moral luhur pancasila tersebut, sehingga menjadi landasan yang kokoh dalam membangun sistem kehidupan bermasyarakat, berbangsa dan bernegara dalam bingkai Negara Kesatuan Republik Indonesia. Pita yang bercengkram kuat oleh kedua kaki burung garuda yang bertuliskan Bhineka Tunggal Ika secara lengkap adalah Bhineka tunggal ika, tan hana dharma mangrwa artinya berbeda-beda tetapi satu, tidak ada Tuhan kedua, dikutip dari kitab sutasoma karangan Mpu Tantular.

Perkembangan pancasila sejak runtuhnya orde baru tanggal 21 Mei 1998, yang kini telah berganti dengan orde reformasi, mengalami kemerosotan yang sangat tajam tentu diantara kita yang sudah tidak hafal dengan rumusan pancasila yang sejak kelahirannya telah dijadikan sebagai way of life bangsa Indonesia. Dahulu, Pancasila sangat membumi di masyarakat karena nilai-nilai 
etika dan moral yang terkandung di dalamnya senantiasa diamalkan dalam kehidupan sehari-hari, tetapi kini nilai-nilai itu kian memudar, seiring dengan pudarnya nilai-nilai kebebasan (freedom value) dalam melaksanakan ibadah sesuai dengan keyakinan yang dianut, hak azasi manusia telah dilanggar, semangat gotong royong mulai menurun, yang ada saat ini adalah penghakiman yang dilakukan oleh kelompok-kelompok radikalisme bagi orang-orang yang yang tidak sealiran atau seiman, bertindak sadis dan anarkis, tidak ada lagi rasa hormat terhadap makhluk ciptaan Tuhan yang paling sempurna di dunia ini yang berdampak pada integritas kebangsaan dan nasionalisme menjadi luntur, munculnya sifat-sifat individualisme, kapitalisme, ekslusivisme dan fanatisme sempit. Forum musyawarah telah menjadi ajang pertengkaran, penghujatan, mencaci maki dengan kata-kata yang tidak pantas, bahkan sampai berkelahi. Fonemena seperti ini terjadi pada wakilwakil rakyat yang kita sebut sebagai dewan yang terhormat yang ditonton oleh ratusan rakyat indonesia.

Pelanggaran etika kepribadian itu akhirnya membuat ide atau gagasan untuk memeperjuangkan hak-hak rakyat dan cita-cita mengangkat harkat dan martabat manusia menjadi bisa dan tidak tercapai. Inilah fonema bangsa Indonesia yang dialami saat ini

\subsection{Deskripsi filosofis pancasila}

Bung Karno dalam pidato pertamanya tanggal 1 Juni 1945 mengartikan bahwa dasar negara Indonesia merdeka sebagai philosophische gronslag, yang meliputi azas fundamental, filsafat dan pola pemikiran mendalam bagi berdirinya Negara Indonesia. Dalam kaitannya dengan hal ini Bung Karno telah mengajukan tiga alternatif ramusan Pancasila (Sudaryanto, 2007: 5) yaitu; Pertama, Pancasila terdiri atas kebangsaan Indonesia, internationalisme atau perikemanusiaan, mufakat atau demokrasi, kesejahteraan sosial dan ketuhanan, Kedua, Tri Sila yang terdiri atas SocioNationalisme yang merupakan kristalisasi dari sila kebangsaan dan perikemanusiaan, sociodemocmtie yang merupakan kristalisasi dari sila demokrasi, kesejahteraan sosial dan Ketuhanan. Ketiga, apabila Trisila dikritalisasi menjadi satu, maka disebut Eka Sila yaitu gotong-royong.

Dalam proses lahirnya Pancasila sebagai dasar Negara Republik Indonesia telah melalui berbagai perdebatan dari para pendiri negara pada waktu itu, yang secara historis berawal dari usaha anggota BPUPKI merumuskan tentang dasar Indonesia merdeka. Dalam pidato Soepomo pada sidang tanggal 31 Mei 1945 menyatakan, bahwa mengenai dasar negara yang hakikat nya adalah menjelaskan tentang pertanyaan; apakah hakikat negara menurut dasar pengertian (staatsidee)! Berkaitan derigan pertanyaan itu Soepomo menegaskan bahwa setiap negara mempunyai keistimewaan sendiri-sendiri sesuai dengan riwayat dan corak masyarakatnya. Oleh karena itu strategi politik pembangunan Negara Indonesia harus disesuaikan dengan kehidupan sosial structur masyarakat Indonesia yang nyata pada masa sekarang ini dan sesuai dengan panggilan zaman. Soepomo menyatakan bahwa aliran pikiran nasional sosialis diartikan sebagai prinsip persatuan antara pimpinan dan rakyat serta prinsip persatuan dalam negara yang secara keselurahan diliputi oleh semangat gotong royong, semangat kekeluargaan, hal ini ngat cocok dengan aliran pemikiran ketimuran dan kebudayaan Indonesia. Dalam kaitan dengan hal ini negara hendak nya mengatasi segala golongan dan perseorangan yang disebut oleh Soepomo sebagai negara integralistik.

Sejalan dengan pemikiran yang disampaikan oleh Soepomo tersebut, Notonegoro (tahun 1980) guru besar Universitas Gadjah Mada memiliki pandangan bahwa Pancasila adalah causa materialis dari adat kebiasaan, kebudayaan dan agama-agama bangsa Indonesia. Prinsip dan pandangan Notonegoro tentang Pancasila yang di sampaikannya dalam pidato pada tanggal 13 
Nopember 1957 (Sidang-III Rapat ke-62 Dewan Konstituante Tahun 1957), yang menyatakan sebagai berikut:

Anggauta Nur Sutan Iskandar;

Pertama karena asas-asasnya sudah kami lukiskan dalam komisi I sebagai pokok-pokok pendirian Partai Nasional Indonesia (PNI) dengan jelas. Kedua karena sejak bermula sudah dibahas diteliti dan ditelaah secara ilmiah oleh cerdik-pandai bangsa kita dan bangsa lain juga.

Pembahasan itu dinamainya Pancasila Dasar Filsafat Negara Republik Indonesia dan diucapkan nya pada tanggal 19 September 1951, ketika Paduka Yang Mulia Ir. Soekarno Presiden Republik Indonesia dianugrahi gelar Doctor Honoris Causa dalam ilmu hukum oleh Universitas Negeri Gajah Mada di Yogyakarta. Anugrah ini didasarkan pada usaha Bung Kamo menciptakan Pancasila, yang dipandang menurut ilmu pengetahuan sudah tahan uji menjadi dasar filsafat negara Republik Indonesia. Pandangan Notonegoro di atas menjadi wawasan pengetahuan yang sangat original tentang filosofi dari Pancasila yang kita warisi hingga saat ini. Sebagaimana diuraikan diatas bahwa Pancasila merupakan watak dan kepribadian bangsa Indonesia yang memiliki dasar peri kemanusian yang universal, dan berlatar belakang bangsa yang berkebudayaan. Berkaitan dengan kebudayaan bangsa Indonesia, maka yang dominan berpengaruh adalah kebudayaan hindu dan budha, hal ini terbukti pada masa pra-kemerdekaan negara Republik Indonesia, bahwa Negara Indonesia pernah disatukan dalam bentuk negara Nusantara pertama yaitu pada zaman kerajaan Sriwijaya dan Negara Nusantara kedua pada zaman kerajaan Majapahit. Pada era kedua negara Nusantara ini kebudayaan hindu dan budha berkembang sangat pesat dan mengalami zaman keemasannya.

Nasikun (tahun 1989) menyatakan bahwa; Pancasila memiliki akar yang kuat bagi pertumbuhan gerakan-gerakan bersifat nasionalisme Indonesia sejak permulaan abad ke-
20, sebagai reaksi terhadap kolonialisme yang telah memenjarakan Bangsa Indonesia selama berabadabad (selama 350 tahun). Pancasila adalah wujud dari nasionalisme itu sendiri. Pancasila sering dikaitkan dengan sistem nilai yang sebelumnya telah tumbuh dan ber kembang dalam kebudayaan Indonesia.

Daoed Yoesoef dalam pandangannya menyatakan bahwa; Pancasila adalah suatu gagasan vital yang berasal dari kebudayaan Indonesia. Dikatakan vital karena dengan gagasan tersebut, manusia dapat menjalankan aktivitas sosialnya dan mengatur hidupnya. Bagi Daoed Yoesoef tidak ada satupun sistem nilai yang tidak memiliki persamaan dengan sistem nilai yang lainnya. Suatu nilai dapat saja bersifat universal dan dapat pula bersifat khas, sesuai dengan produk dari Negara yang bersifat spesifik. Berdasarkan kerangka tersebut, maka nilai-nilai Pancasila memiliki makna yang bersifat universal dan berkaitan dengan sistem nilai yang lain, tetapi sekaligus dapat memiliki makna spesifik yang berkaitan dengan sejarah bangsa Indonesia (Sudaryanto, 2007: 3).

Perjalanan negara Republik Indonesia dengan dasar negara Pancasila dan UUD 1945 mengalami banyak cobaan, terutama di bidang politik pada masa orde lama, bahwa negara kita pernah diganti menjadi RIS, tetapi tidak lebih dari satu tahun dan akhirnya kembali lagi ke negara kesatuan Republik Indonesia dengan tekad menjalankan Pancasila dan UUD 1945 secara murni dan konsekwen (Dekrit Presiden 5 Juli 1959).

Tujuh tahun kemudian terjadi masa transisi dari orde lama ke orde baru, ditandai dengan penyerahan surat perintah sebelas Maret (Supersemar) pada tanggal 11 Maret 1966 dari Presiden Pertama Republik Indonesia Bung Karno kepada Soeharto. Pada zaman orde baru, Pancasila mengalami masa keemasan, karena setiap warga Negara Indonesia wajib menghayati dan mengamalkan Pancasila sebagai falsafah hidup 
bermasyarakat, berbangsa dan bernegara. Program ini dinamakan Program P-4 yaitu Pedoman Penghayatan dan Pengamalan Pancasila. Pemerintahan orde baru berlangsung cukup lama yaitu selama 32 tahun. Menurut kaum reformis selama masa pemerintahan orde baru, demokrasi dikatakan telah berjalan semu, karena pemerintahan dikendalikan oleh kekuatan militer dengan menjalankan sistem dwi fungsi ABRInya. Bagi kalangan aktivitis pemerintahan orde baru identik dengan fasisme timur. Dalam masa orde baru ini demokrasi benar-benar terpasung, tetapi sebalik nya situasi pertahanan dan keamanan benar-benar terjaga dengan baik, dunia sangat menghormati kedaulatan Indonesia semasa Soeharto berkuasa, dan kala itu beliau diakui sebagai pemimpin utama Negara Non Blok, disebut juga sebagai kekuatan dunia ketiga, yang ada di antara dua negara adidaya yaitu blok barat (NATO) dan blok timur (Uni Sovyet). Saat ini, Uni Sovyet telah terpecah belah menjadi beberapa negara, yaitu; Rusia, Urbekistan, Bosnia, Cesnia, Ukraina, dll.

Pada tanggal 21 Mei 1998 pemerintahan Orde Baru tumbang oleh kekuatan reformasi yang digulirkan para aktivis bergabung dengan kekuatan mahasiswa. Seiring dengan runtuhnya kekuasaan Soeharto, zamanpun telah berganti pula dari orde baru menjadi orde reformasi. Pandangan kaum reformis tersebut diatas membuat perasaan menjadi pesimistis terhadap kelestarian dan keutuhan nilai-nilai Pancasila. Ada kekhawatiran tentang semakin menurunnya nilai-nilai etika dan moral Pancasila, karena ada kecenderungan sebagian kecil masyarakat bahwa; yang menganggap nilai-nilai yang terkandung dalam Pancasila sudah tidak relevan lagi dengan situasi dan kondisi masyarakat di era reformasi ini. Pandangan seperti ini sering terlontar dari mereka yang bersikap apriori terhadap Pancasila, seakan tidak menghormati perjuangan para pendiri negara yang telah meletakkan dasar-dasar Negara Indonesia yang merdeka, berdaulat dan dihormati oleh bangsa-bangsa di dunia. Para pendiri bangsa 4 berjuang dengan penuh keikhlasan, tanpa pamrih, dengan satu tujuan membangun kelangsungan hidup rakyat Indonesia, bebas dari penjajahan, merdeka dalam bingkai persatuan dan senantiasa menjunjung tinggi agama dan menghormati adat serta budaya Indonesia.

Dalam perkembangannya selama tiga zaman, di mulai dari orde lama, orde baru dan orde reformasi serta mengamati degradasi penghayatan dan pengamalan dari nilai-nilai Pancasila di masyarakat.

\subsection{Zaman Kerajaan Hindu Nusantara}

Kepulauan Nusantara terdiri dari ratusan suku bangsa, yang sehari-hari diantaranya sering kita sebut suku Jawa atau suku Sunda, Suku Batak, Suku Aceh, Suku Bugis, Suku Banjar, Suku Bali, Suku Ambon, Suku Dayak, Suku Irian dan lain lainnya. Mereka masing-masing mempunyai bahasa daerah atau disebut sebagai bahasa ibu, adat-istiadat dan seni budaya. Walaupun berbeda, namun masih terdapat benang merah yang masih dianggap bertalian antara yang satu dengan lainnya, sebadai bentuk asimilasi di dalam bahasa, adat istiadat dan kesenian mereka.

Nenek moyang bangsa Indonesia berasal dari daerah Yunan Cina Selatan. Ketika itu daerah Yunan dilanda peperangan, sehingga sebagian besar masyarakat Yunan meninggalkan tanah airnya, berlayar menempuh laut cina selatan, semenanjung Malaya, Filipina dan akhir nya mereka menempati kepulauan Nusantara dari sumatera sampai Irian, bahkan ada yang tiba di pulau-pulau kecil yang bertaburan di samudra pasifik.

Perpindahan penduduk yunan kala itu berlangsung selama ribuan tahun lalu, mereka pindah tidak sekaligus, tetapi secara perlahanlahan. Yang datang lebih dahulu di kepulauan Nusantara mempunyai peralatan dari batu, sehingga masa itu debut zaman batu. Kemudian yang datang belakangan mempunyai peralatan dari logam seperti ; perunggu dan besi, maka disebut zaman logam. Beberpa peninggalan alat-alat 
berupa batu dan logam telah ditemukan oleh para arkeolog di nusantara. Dari beberapa peninggalan yang telah ditemukan, maka dapat disimpulkan bahwa nenek moyang bangsa Indonesia sejak dahulu telah mengenal pertaruan atau pertanian atau perkebunan, perternkan dan perdagangan. Dengan adanya pertanian itu berati mereka telah hidup sebagai kelompok masyarakat pemujiman yang bertempat tinggal tetap dengan mendirikan rumah yang sederhana diatas tiang sebagai tempat tinggal. Untuk menyambung hidupnya, mereka mencari makanan dengan cara berburu dan mengumpulkan makanan yang ada di alam sekitarnya.

Nenek moyang bangsa Indonesia mempercayai adanya makhluk halus dan kekuatan gaib yang ada pada benda, pohon, binatang dan peristiwa alam yang menakutkan misalnya ; petir, letusan gunung berapi. Mereka memuja leluhurnya, yang diyakini tinggal di gunung yang tinggi dan pohon yang besar. Kepercayaan nenek moyang ini masih ada sampai sekarang. Bukti-bukti peninggalan sejarah zaman nenek moyang hanya berupa peralatan pertanian dan alat-alat yang terbuat dari batu dan logam, karena sampai dengan abad ke 5 nenek moyang bangsa Indonesia belum mengenal tulisan. Kemudian pada permulaan zaman prasejarah yang dimulai abad $\mathrm{V}$, budaya tulis menulis mulai dikenal melalui kebudayaan hindu. Masuknya kebudayaan ini karena sejak abad I Masehi, laut di kepulauan Nusantara ramai dilayari oleh kapal-kapal para pedagang dari India dan Cina. Nenek moyang bangsa Indonesia tentu ikut serta dalam perdagangan itu, maka melalui perdagangan itulah kebudayaan hindu dan budha tersebut masuk ke wilayah nusantara.

\subsection{Pengaruh Kebudayaan Hindu terhadap Pancasila}

Sejarah telah membuktikan bahwa berdasarkan tinjauan aspek filosofis dan historis, lahirnya Pancasila sangat erat sekali dengan etika dan budaya asli bangsa Indonesia. Nilai-mlai ini telah berkembang jauh, sebelum Indonesia merdeka. Berdasarkan bukti sejarah; etika dan kebudayaan yang paling banyak berpengaruh terhadap bangsa Indonesia sebelum berkembang dengan pesat pada masa kerajaan Majapahit.

Berdirinya kerajaan Majapahit pada saat itu telah memberi nuansa religius dan pengaruh yang besar dalam perkembangan kebudayaan hindu di Indonesia. Dalam sejarah perkembangan bangsa Indonesia, budaya hindu telah banyak memberi warna kehidupan dan norma-norma perilaku yang berkembang baik di masyarakat. Hal ini diketahui berdasarkan bukti sejarah tentang kebudayaan hindu di Indonesia.

Secara etimologi Pancasila berasal dari bahasa sansekerta, yaitu; Panca artinya lima, Sila artinya dasar, dengan demikian maka Pancasila artinya lima dasar. Berdasarkan uraian diatas, maka Pancasila berakar dari budaya asli Indonesia yang di perjuangkan dengan penuh pengorbanan yang tidak ternilai harganya; pengorbanan jiwa raga, tetesan darah, dan harta benda, yang tidak dapat dilupakan begitu saja, karena Pancasila adalah pedoman hidup bangsa Indonesia yang memuat ajaran etika dan moral yang banyak dipengaruhi oleh kebudayaan hindu.

Untuk menghargai perjuangan para pendiri Negara yang telah berjuang dengan segala pengorbanan; jiwa raga, luirta benda untuk satu tujuan, Merdeka. Pancasila perlu terus dipahami, dihayati dan diamalkan dalam kehidupan bermasyarakat, berbangsa dan bernegara, karena Pancasila adalah falsafah hidup bangsa, sumber dari segala sumber hukum, dan Pancasila adalah dasar Negara Republik Indonesia.

Pancasila lahir pada jaman perjuangan dan digali dari nilai-nilai budaya asli bangsa Indonesia jauh sebelum Indonesia merdeka, karena dalam sejarah perkembangan bangsa Indonesia, sebelum Indonesia merdeka, Indonesia pernah disatukan dalam Negara Kerajaan Sriwijaya dan Majapahit, sebagai Negara yang menguasai Nusantara dari 
sabang sampai ke meraoke. Negara pada masa ini dipengaruhi oleh nilai-nilai kebudayaan Hindu dan Budha. Namun kejayaan bangsa Indonesia di bawah panji-panji kerajaan Majapahit ini mengalami keruntuhan sejak masuk nya para pedagang dari portugis pada awal abad ke-XV (tahun 1511) dan kemudian disusul oleh kehadiran bangsa Belanda pada awal abad ke-XVI (tahun 1602).

Setelah runtuhnya kerajaan Majapahit pada abad-XVI, maka kebudayaan hindu hanya bertahan di suatu pulau kecil dan oleh para brahmana hindu yang melaksanakan ekspedisi ke pulau ini disebut Pulau Bali. Pulau ini akhirnya dikenal sebagai Pulau Dewata, karena para brahmana yang menetap dan moksa di pulau ini banyak mengajarkan ajaran agama hindu dan mendirikan pura-pura penting sebagaimana kita warisi sampai sekarang, yaitu: Pura Kahyangan Jagat yang berpusat di Besakih dan pura Dang Kahyangan yang didirikan untuk menghormati para brahmana yang mengajarkan dan menyebarkan agama hindu di Bali.

Secara ontologis kesatuan sila-sila Pancasila sebagai suatu sistem bersifat hierarkis dan berbentuk piramidal dapat dijelaskan sebagai berikut:

1.Sila ke -1. Bahwa pada hakikatnya adanya Tuhan adalah karena diri-Nya sendiri, Tuhan sebagai causa Prima. Artinya, segala sesuatu yang ada termasuk manusia ada karena diciptakan Tuhan (akibat dari adanya Tuhan).

2.Sila ke-2. Manusia sebagai pokok dari suatu negara, maka muncul sebuah negara yang merupakan persekutuan hidup bersama yang beranggotakan manusia.

3.Sila ke-3 Negara adalah akibat dari adanya manusia yang bersatu.

4. Sila ke-4 Sebagai akibat dari manusia yang bersatu, akan terbentuk rakyat yang merupakan unsur suatu negara di samping wilayah dan pemerintah. Dengan kata lain, rakyat adalah totalitas dari individu-individu dalam negara yang bersatu.

5.Sila ke-5 Dengan terbentuknya suatu pemerintahan, maka akan muncul suatu tujuan yakni keadilan, yang pada hakikatnya merupakan tujuan dari lembaga hidup bersama yang disebut negara.

Ditinjau dari makna filosofisnya, bahwa kelima Sila dari Pancasila itu memiliki nilai-nilai religius yang menjadi inti dari keyakinan agamaagama yang ada di I ndonesia, teratama agama hindu, apabila dikaitkan dengan ajaran Panca Sraddha, maka makna terdalam yang terkandung dalam Pancasila adalah nilai-nilai etika religius yang sangat tinggi dan universal. Secara detail nilai-nilai religius tersebut akan diuraikan sebagai berikut:

\section{Sila Pertama: Ketuhanan Yang Maha Esa}

Ditinjau dari kedudukannya sila-sila dalam Pancasila, maka Sila Ketuhanan Yang Maha Esa, sudah sepantasnya dan sangat tepat ditempatkan pada urutan pertama. Sebagai bangsa yang beragama dan beradab, maka penghormatan tertinggi hanyalah dilakukan kepada Tuhan. Dalam sila pertama Pancasila disebut kan, hanya Tuhan sebagai zat yang maha tinggi dan sempurna, dan sebutan Tuhan dapat diterima oleh semua agama yang ada di dunia termasuk di Indonesia.

Dalam ajaran agama hindu yaitu Panca Sraddha artinya lima kepercayaan agama hindu, dinyatakan dalam Sradha pertama, yaitu "Percaya dengan ada nya Ida Sanghyang Widhi Wasa". Hal ini bermakna bahwa dalam ajaran agama hindu, yang paling utama dan pertama kepercayaan itu diberikan adalah kehadapan Ida Sang Hyang Widhi Wasa, sebagai suatu zat yang maha sempurna, maha pencipta, maha kuasa, maha besar, dan maha pengasih.

Demikian pula dalam lambang Negara Republik Indonesia terdapat pita yang dicengkram oleh kedua kaki "Garuda Pancasila" yang bertuliskan "Bhineka Tunggal Ika”. Kalimat lengkap dari tulisan tersebut adalah bhineka 
tunggal ika, tan hana dharma mangrva yang artinya: berbeda itu satu, tidak ada Tuhan kedua, Sasanti tersebut bersumber dari kitab Sutasoma karangan Mpu Tuntular, hal ini membukti kan bahwa nilai-nilai kebudayaan Hindu berpengaruh sangat besar dalam proses lahirnya pancasila.

2. Sila Kedua: Kemanusiaan Yang Adil dan Beradab

Setelah menghormati Tuhan sebagai suatu yang paling utama, maka penghormatan yang kedua diberikan kepada sifat-sifat dasar yang berkaitan dengan manusia, yaitu; bahwa hakikat dasar manusia adalah mahluk yang memiliki cinta kasih, ingin diperlakukan sccara adil dan mahluk yang beradab, karena sesungguhnya ia menginginkan ketentraman, kedamaian dan kebahagiaan. Manusia adalah mahluk utama dan mulia yang diciptakan oleh Tuhan, maka ia harus memiliki sifat-sifatyang mulia.

Dalam Panca Sradha (lima kepercayaan Hindu), disebutkan pada Sradha ke-2, yang menyatakan bahwa Percaya dengan adanya Atman atau Roh para leluhur. Berdasarkan ajaran tersebut, atman bersemayam di dalam diri setiap manusia dan mahluk hidup lainnya. Untuk menghormati Atman yang merupakan percikan kecil dari Brahman, maka penganut Hindu wajib menghormati manusia sebagai wadah dari sang Atman. Dalam ajaran Hindu hormat-menghormati antar sesama manusia dalam kehidupan masyarakat dikenal dengan ajaran tat tvam asi yang artinya engkau adalah dia, bagi umat Hindu etika ini wajib dilakukan, karena manusia adalah mahluk ciptaan Tuhan.

\section{Sila Ketiga: Persatuan Indonesia}

Menurut Machiapelli manusia disebut sebagai zoon politicon (mahluk sosial). Sebagai mahluk sosial satu sama lainnya akan saling memerlukan dan saling ketergantungan, karena manusia tidak dapat hidup sendiri, ia memerlukan manusia lain dalam aktivitasnya untuk memenuhi kebutuhan hidupnya. Di dalam ajaran agama Hindu manusia diajarkan untuk selalu bersatu, antara satu dengan lainnya, sebagaimana para dewa yang ada di sorga selalu bersatu, hal ini tertuang dalam $R g$. Veda yang menyatakan sebagai berikut:

Om sam gacchadvam sam vadadvam sum vo manamsi janatam deva bhagam yatha purve samjnana apusate (Rg. Veda X.I91.2)

Artinya:

Om Hyang Widhi Wasa, kami berkumpul ditempat ini, berbicara satu dengan yang lain untuk menemukan kesatuan pikiran sebagai halnya para dewa pada jaman dahulu bersatu.

Om sam samani va akutih

Samana hridayani vah

Samanam astu vo mano

Yathavah susahah sati (Rg. Veda X.I91.3) Artinya:

Om Hyang Widhi Wasa, tuntunlah kami agar sama dalam tujuan, sama dalam hati, bersatu dalam pikiran, sehingga kami dapat hidup bersama dengan bahagia

Dalam Rg.Veda X.I91.2 diatas terdapal kalimnl yang perlu dipahami, yaitu; kata sebagaimana hulnya para dewa dahulu bersatu. Untaian kata-kata tersebni bcrmakna bahwa manusia dalam menjalani kehidupan nya, wajib bermusyawarah, berbicara satu dengan yang laiunya untuk menemukan kesatuan pikiran dalam mencapai tujuan. Dengan sloka tersebut, maka tidak ada alasan bagi manusia untuk bertengkar, bermusuhan, apalagi saling mcnyakiti atau saling membunuh, karena hal itu bertentangan dengan kehendak para dewa sebagai manifestasi dari Ida Sanghyang Widhi Wasa.

Demikian juga apabila sloka Rg.Veda $X .191 .2$ tersebut dilaksanakan, maka keinginan untuk memohon anugrah kehadapan Ida 
Sanghyang Widhi Wasa sebagai mana dinyatakan dalam sloka Rg.Veda X. 191.3 agar kita selalu sama dalam tujuan, sama dalam hati dan sama dalam pikiran untuk mencapai kebahagiaan di dunia, niscaya akan membuat para dewa senang, sehingga apa yang dimohonkan kehadapanNya akan senantiasa mendapat kan anugrah kebahagiaan.

Memaknai nilai persatuan yang terkandung dalam Sila-3 dari Pancasila, dikaitkan dengan nilai religius yang terkandung dalam sloka Rg.Veda tersebut diatas, maka nilai-nilai persatuan yang terkandung dalam sila-ketiga Pancasila merupakan nilai-nilai sosial religius yang sangat penting dalam membangun keutuhan bangsa dan negara. Nilainilai persatuan yang terdapat dalam Sila ke-3 Pancasila tertuang.

Dalam Rg.Veda. 191.2, hindu mengajarkan kepada para pengikutnya untuk selalu bersatu dalam menjalani kehidupannya di dunia, untuk mencapai tujuan hidup menurut ajaran hindu "moksartham jagadhita ya ca itti dharma ". Setelah kerajaan Majapahit runtuh, maka nilai-nilai persatuan tersebut telah dijadikan sebagai dasar dalam membangun sistem adat-istiadat Bali (banjar adat, desa adat). Dalam kehidupan masyarakat adat di Bali, nilai-nilai ini sangat ditaati dan menjadi ruh dari peraturan awig-awig adat yang berkembang hingga saat ini.

4. Sila-kempat: Kerakyatan yang dipimpin oleh hikmatatau kebijaksanaan dalam permusyawaratanatau perwakilan

Berkaitan dengan komunikasi harmonis yang harus dilakukan oleh setiap orang, maka nilainilai sosial ini akan menjadi embrio dari hubungan kemanusiaan. Dalam ajaran etika agama hindu disebut tattvam asi artinya engkau adalah dia. Dalam pengamalan nilai-nilai luhuryang terkandung dalam sila ke-4: kerakyatan yang dipimpin oleh hikmat atau kebijaksanaan dalam permusyawaratan perwakilan. Apabila sila ke4 ini diuraikan, maka yang harus dimaknai dalam sila ini adalah nilai-nilai antara lain; nilai kerakyatan, nilai kepemimpinan, nilai kebijaksanaan, nilai permufakatan baik melalui musyawarah atau keterwakilan.

- Nilai kerakyatan : dimaksudkan bahwa dalam mem bangun kesepakatan harus dimulai dari rakyat, oleh rakyat dan sebesar-besarnya untuk kepentingan rakyat.

Nilai kepemimpinan : yang dimaksud dalam nilai-nilai ini adalah pemimpin yang memiliki karakter atau sifat-sifat sebagaimana diatur dalam 11 azas kepemimpinan, juga harus mengikuti nilai-nilai kepemimpinan hindu yaitu Asta Brata.

Nilai kebijaksanaan : nilai kebijaksanaan dalam sila ke-4 harus dijadikan sebagai pedoman dasar dalam menetapkan suatu keputusan.

Nilai musyawarah : nilai-nilai ini merupiakan implementasi dari sifat-sifat demokratis yang harus dimiliki oleh setiap .pemimpin, apabila nilai-nilai ini tidak dilaksanakan, maka pemimpin akan menjadi otoriter.

Nilai-nilai kepemimpinan sebagaimana diuraikan di atas, dalam ajaran hindu ditemukan dalam kekawin Ramayana ketika Gunawan Wibisana kembali keAlcngka Pura menjadi raja menggantikan kakaknya Rahwana yang telah gugur dalam peperangan nielawan Sri Rama. Sebelum Wibisana berangkat ke Alengka Pura, terlebih dahulu Sri Rama memberikan ajaran Asta Brata kepada Wibisana, agar Wibisana menjadi Raja yang baik dan bijaksana serta dicintai oleh rakyatnya. Dalam ajaran tersebut Sri Rama secara tegas menyebut kan 8 sifat dewa atau Asta Brata yang harus diikuti oleh Wibisana. Ajaran kepemimpinan ini diuraikan dalam Kekawin Ramayana Sarga.21 yang menyatakan sebagai berikut:

Prayatna ring ulah atah ngwangprabhu Mdweha tuladan tiruning sarat Yadin salah ulah sarat kabeh Fernanda pada sang mawatig rat tinut 
Artinya:

Berhati-hatilah bertmat, apalagi menjadi pemimpin

berikanlah contoh yang patut diturut oleh masyarakat, kalau salah berbuat maka akan hancur lah masyarakat seluruhnya, sebab bagi masyarakat, pemimpin rakyatlah yang akan dituruti.

lawannira kinon aken katyvanga apan ana bhatara mjunggwing sira wulung hyanga pupul ryawak sang prabhu

dumeh sira maha prabhawa sana artinya:

dan lagi beliau wajib dihormati, karena ada kekuatan dewabersemayam pada diri beliau, delapan dewa manifestasiTuhan bersemayam pada diri beliau, itulah sebabnya beliau sangat berwibawa tidak ada yang menyamai.

Sanghyang Indra, Yama, Chandra, Njla, Kwera, Baruna, Agni, Nahan Wwalu strata, maka angga sang bhupati Matang sira ninistha asta brata Artinya:

Sanghyang Indra, Yama, Chandra, Bayu, Sanghyang Kwera, Waruna, dan Agni, itu semuanya delapan, semua beliau itu menjadi pribadi sang raja, oleh sebab itulah harus memuja asta brata.

Nihan bratani Sanghyang Indra lapan,

Sirangudari aken tumprepting jagat

Sim ta tuladanta indra brata

Sabhanaya udanta manglyabirat Artinya:

Inilah bratanya Sanghyang Indra yang patut diikuti,

beliaulah menurunkan hujan untuk kemakmuran jagat, beliau patut diikuti yang disebut Indra Brata, sangat utama tujuan itu yang menyuburkan rakyat.

Yama brata dumandha karma ala Sirakana malting mating yar pejah

Umilwa kita malwa ngolah salah

Asing ngumamrang sarat prihpati Artinya:

Brata Sanghyang Yama menghukum orang yang berbuat salah, beliaulah yang menghukum roh pencuri kalau sudah mati, patutlah kita ikut menghukum orang yang salah, setiap yang membikin kacaunya masyarakat patut dilenyapkan.

\section{Bhatara rawi mengisep Welana}

Endi tan kara saneh-saneh denira

Samangkana kita talap pangguben Tata gelis yaka suryabrata

Artinya:

Kewajiban Sanghyang Surya adalah mengisap air,

tidak dengan tergesa-gesa tapi sangat berhatihati beliau, demikianlah kamu contoh yang nyata dilihat, tidak tergesa-gesa itulah brata Sanghyang Surya.

Sasi brata umar sukang rat kabeh, ulah ta mrdu komala, yan katon guyun ta mamanis ya tulya mrta,

asing matuha pandita ta swagata. Artinya:

Kewajiban Sanghyang Chandra adalah membuat senang semua masyarakat, laksanamu agar simpatik (menarik), dipandang senyummu supaya manis berseri-seri bagaikan air kebidupan (amrta), setiap orang tua dan pandita supaya dihormati.

Anginta kita yan panginta ulah, kuma wruh ana budining rat kabeh, sucara yapanonta tatan katon, 
ya dibya guna suksma bayu brata. Artinya:

Agar seperti angin itulah engkau ketika menyelidiki keadaan rakyat, agar engkau mengetahui kehendak masyarakat yang sebenarnya, kepandaian sebagai penglihatanmu yang kamu tidak ketahui, itulah sifat utama yang amat rahasia bernama bayu brata.

\section{Mamukya nguabogasinambin nginak taman pene,} pengan pangan muang nginum, menandanga mabusana mahyas, nahata dhanada brata nuntirun. Artinya:

Pada saat menikmati makanan dan hiburan, jangan terlalu tamak dengan makan, minum, demikian juga berpakaian dan menghias diri, itulah bebratan Sang hyang Kwera yang patut ditiru.

\section{Bhrata bharunangga senjata,}

Maha wisaya napa pasa ngapus, Strata tuladanta pasa brata,

Kita papusanang watek durjana. Artinya:

Kewajiban Sanghyang Bharuna selalu memegang senjata, sangat bertuah dililit oleh nagapasa, beliau itu patut diikuti bratanya, begitulah engkau harus momusnahkan semua yang berbuat jahat.

\section{Lana ngesengi satru bahnibrata} Galakta rimusuh yeka puwi Asing saina santa sirnapasah Artinya:

Yang selalu membasmi musuh itu adalah agni brata, semangat membasmi musuh itu sebagai kobarannya, setiap musuh yang dihadapi hancur lebur, yang demikian itulah bratanya Sanghyang Agni.
Nahanta guna sang rumaksengjagat, Gina lana ginasti niwa,

Yang tutanta yatu maniktekana,

Ulahma seseran paseseran magang.

Artinya:

Demikianlah kewajiban dari orang yang menguasai masyarakat, karena itu selalu dipelajari dan dimusya warahkan, itu patut ditiru adikku, bagaikan kalung manik yang demikian perilaku adik menguasai masyarakat sebagai pegangan utama.

Apa yang telah diuraikan di atas, merupakan nilai nilai yang wajib diterapkan oleh seorang pemimpin, karena asta brata adalah sabda Sri Rama sebagai awatara Dewa Visnu, yang bukan saja sekedar nasehat atau petunjuk kepada Wibisana, melainkan merupakan ajaran tentang kepemimpinan yang disebut Nitisastra. Nilai-nilai kepemimpinan yang terkandung dalam Pancasila, telah ada sebelumnya dalam ajaran hindu dan diuraikan secara rinci dalam Kekawin Ramayana yang sangat populer dan telah dijadikan sebagai filsafat etika dalam ajaran Nitisastra. Dalam Nitisastra telah dijelaskan bahwa dalam diri seorang pemimpin telah dianugrahi oleh delapan dewa yang wajib ditiru dan dijalankan oleh seorang pemimpin.

5. Sila-kelima: Keadilan sosial bagi seluruh rakyat Indonesia Nilai-nilai yang terkandung dalam Sila ke-5 adalah nilai-nilai keadilan, nilai-nilai sosial dan nilai-nilai kerakyatan. Dalam mengamalkan nilainilai yang terkandung dalam sila ke-5, maka harus dipahami terlebih dahulu nilai-nilai yang terdapat dalam butir butir sila ke-5 sebagai berikut:

- Nilai keadilan : nilai ini menjadi hakikat dasar dari sifat-sifat manusia, siapapun manusia di dunia ini dipastikan ingin diperlakukan secara adil. Nilai-nilai tersebut antara lain; sifat tidak 
memihak, objektif dalam menilai masalah dan proporsional.

- Nilai sosial : nilai ini menjadi kodrat dasar kehidupan manusia, yang sejak lahir memerlukan bantuan orang lain untuk menjaga kelangsungan hidupnya. Setelah dewasa manusia juga harus tetap menjalin hubungan dengan manusia yang lain, karena itu mamisi;i disc-but oleh Machiapelli sebagai zoon politicon (mahluk sosial), karena tidak seorangpun manusia dapat hidup sendiri.

Tentang sifat-sifat sosial manusia, dalam bhagawad gita III. 10 disebutkan: setelah menciptakan manusia, berkata : dengan (cara) ini engkau akan berkembang...”. Berdasarkan kutipan sloka tersebut, maka salah satu kewajiban manusia lahir ke dunia adalah berkembang, untuk dapat berkembang atau mencruskan keturunannya maka manusia wajib menjalin hubungan harmonis dan untuk memperoleh kebajikan, maka manusia wajiblah saling memberi, dalam bhagawadgita III. 10 dan 11 diuraikan sebagai berikut:

\section{Saha yajnah prajah srstva Purovaca prajapatih Anena prasavisyadhvam Esa vo 'stv ista-kama-dhuk} Artinya:

Sesungguhnya sejak dahulu dikatakan bahwa Tuhan setelah menciptakan manusia melalui yajna, berkata: dengan cara ini engkau akan berkembang, sebagaimana sapi perah yang memenuhi keinginanmu sendiri.

\section{Devan bhavayatanena}

Te deva bhavayantu vah

Parasparam bhavayantah

Sreyah param avapsyatha

Artinya:

Adanya para dewa adalah karena ini, semoga mereka menjadikan engkau demikian, dengan saling memberi engkau akan memperoleh kebajikan paling utama.

Berdasarkan kedua sloka bhagawadgita tersebut di atas, maka sangatlah jelas bahwa berkembang yang esensinya menjalin hubungan harmonis adalah wajib menurut ajaran hindu. Demikian juga saling memberi yang dipersyaratkan agar manusia mem peroleh kebajikan yang paling utama, juga menjadi kewajiban yang harus diamalkan dalam kehidupan manusia di dunia.

Selain sloka tersebut diatas, agama Hindu juga mengajarkan tentang bagaimana seharusnya manusia berbuat agar dalam kehidupannya memperoleh kesejahteraan dan memelihara ketertiban sosial, hal ini tertuang dalam sloka Bhagawadgita III.25 yang menyatakan:

\section{Saktah karmany avidvamso Yatha kurvanti bharata Kuryad vidvams tathasaktas \\ Cikirsur loka-sangraham}

Artinya:

Seperti orang dungu yang bekerja karena keterikatan atas kerja mereka, demikianlah harusnya orang pandai bekerja tanpa kepentingan pribadi,wahai bharata melainkan untuk kesejahteraan dan ketertiban sosial

\section{Kesimpulan}

1. Yang dimaksud dengan filsafat Pancasila adalah kerangka berpikir dan cara berpikir yang dipilih, diakui, serta dijadikan landasan dalam setiap aktivitas kehidupan berbangsa dan bernegara Indonesia.

2. Itulah keyakinan umat Hindu terhadap Pancasila, lima sila yang memiliki satu kesatuan yang utuh dan bulat guna dilaksanakan secara serasi dan utuh pula. Pada hakekatnya sila demi sila yang ada dalam Pancasila, yang mempunyai nilai yang sangat luhur dan mulia dalam kehidupan manusia dalam arti universal. Pancasila menjadi ideologi nasional, dimana 
nilai-nilai luhur Pancasila dijabarkan dalam silasila Pancasila. Pancasila merupakan idiologi pengayom bagi ragam polarisasi idiologi dan agama di Indonesia.

3. Hubungan antara tiap-tiap sila dalam Pancasila yakni tiap-tiap sila dari kelima sila yang ada merupakan kesatuan yang saling berhubungan, saling berhubungan, dan saling bekerja sama membentuk kesatuan yang bulat dan utuh. Dimana sila yang satu mengandung dan melengkapi sila yang lainnya, sehingga tiap-tiap sila tidak bisa berdiri sendiri.

4. Peran Filsafat Pancasila dalam kehidupan berbangsa dan bernegara adalah sebagai paradigma. Dalam artian Filsafat Pancasila merupakan sumber dari segala sumber hukum yang ada di Indonesia, baik dalam segi politik, sosial, ekonomi, hubungan internasional, maupun dalam segi religius.

\section{DAFTAR PUSTAKA}

Dewanto, Tahun 2005. Buku terjemahan Rg. Veda Samhita_——— penerbit Paramita, Surabaya.

Hartono Dimyanti, Tahun 2010. Memahami Makna Pembukaan ______ Undang-Undang Dasar 1945-Penerbit Nuansa Aulia Bandung.

Idea Good, Tahun 2009. UUD'45 dan perubahannya plus profil

Menteri Kabinet Indonesia Bersatu-II (2009-2014)—Penerbit Good Idea Pustaka, Jakarta.

Kansil,C.S.T, Tahun 2000. Pancasila dan Undang-Undang _____ Dasar 1945-Penerbit PT.Pradnya Paramita.

Pudja, Gede, Tahun 2005. Bhagawad Gita (Pancama Veda) Penerbit Paramita, Surabaya.
Sudaryanto, Tahun 2007. Filsafat Politik Pancasila, Reflksi atas teks perumusan Pancasila-penerbit Kepel Press, - Yogyakarta.

Yunan S.Ahmad,Soerjanegara, Tahun 2000. Pendidikan Pancasila dan kewarganegaraan-Penerbit Angkasa,Bandung.

Notonegoro, Tahun 1959. Pancasila Dasar Filsafat Negara RI, Perpustakaan Fakultas Ekonomi Universita Gadjah Mada, Yogyakarta.

Nugroho Dewanto, Tahun 2006. Tanya Jawab Seputar Pancasila dan UUD 1945. 